EXTENDED REPORT

\title{
p53 in rheumatoid arthritis synovial fibroblasts at sites of invasion
}

\author{
C A Seemayer, S Kuchen, M Neidhart, P Kuenzler, V Řihošková, E Neumann, M Pruschy, \\ W K Aicher, U Müller-Ladner, R E Gay, B A Michel, G S Firestein, S Gay
}

Ann Rheum Dis 2003;62:1139-1144. doi: 10.1136/ard.2003.007401

See end of article for authors' affiliations ......................

Correspondence to: Dr S Gay, Centre of Experimental Rheumatology, Gloriastrasse 25, $\mathrm{CH}$ 8091 Zürich, Switzerland; steffen.gay@usz.ch

Accepted 15 March 2003
Objective: To analyse the functional response of p53 in rheumatoid arthritis synovial fibroblasts (RASF) in vitro and in vivo and to investigate whether activation of p53 modulates the destructive process of RASF. Methods: RASF and controls grown on chamber slides were either directly examined with DO7 anti-p53 antibodies by immunofluorescence or irradiated with $10 \mathrm{~Gy} x$ rays and analysed time dependently for the expression of $\mathrm{p} 53$. The percentage of positive cells was evaluated by a quantitative scoring system. RASF and normal (N) SF cultured in vitro were co-implanted with human cartilage in SCID mice for 60 days. Consecutively, the invasion score was evaluated, and the number of p53 positive cells was determined at the sites of invasion by immunohistochemistry. In addition, synovial tissues from RA, osteoarthritis, and normal synovia were stained with DO7 antibodies.

Results: In vitro the rate of expression of p53 in RASF was low $(<5 \%)$, but transiently inducible by ionising irradiation (50\%). In vitro low p53 expressing RASF disclosed, when invading articular cartilage, a nuclear p53 signal in $20 \%$ of the cells, indicating the induction of p53 in a distinct population of RASF during the invasive process.

Conclusions: These data suggest an inductive p53 response at sites of cartilage invasion during the destructive process driven by activated RASF.
$\mathrm{R}$ heumatoid arthritis (RA) is a chronic inflammatory disease characterised by synovial hyperplasia, pathological immune phenomena, and progressive joint destruction. $^{1}$ Increasing evidence has been presented that activated RA synovial fibroblasts (RASF) are key players in the destruction of the joint. ${ }^{2}$ The most striking evidence is that RASF invade deeply and destroy human articular cartilage independently from inflammatory processes, when co-implanted under the renal capsule of SCID mice. ${ }^{3}$

However, it is still not clear how these cells are activated and develop their aggressive behaviour when they are in close contact with cartilage. On the one hand, overexpression of p53 in RA synovial lining cells has been noted with immunohistochemistry, and the protein documented in cultured RASF using Western blot analysis. ${ }^{4}$ On the other hand, studies from Australia and Japan have detected only a limited expression of p53 in RA tissues of about $1 \%$ of the cells. ${ }^{5} 6$ A slightly higher expression of $\mathrm{p} 53$ was present in a study from Tak et al, which found on average around $1-5 \%$ p53 positive cells, when the tyramine enhancement technique was used. ${ }^{7}$ Furthermore, mutations in the p53 gene have been reported by three groups from America, Japan, and France, although the exact prevalence and functional sequelae remain undefined..$^{8-10}$ Moreover, in RA samples from Germany no mutations in the p53 gene could be detected, whereas in samples from America p53 mutations were present, giving rise to the hypothesis that regional differences of p53 mutations in RA may exist. ${ }^{11}$ Our group has shown in functional studies using SCID mice that synovial fibroblasts transfected with the human papilloma virus E6 inhibited endogenous p53 in these cells, which increased invasiveness into the co-implanted cartilage. ${ }^{12}$ In view of these observations, the role of p53 in RASF in the destructive process of cartilage and bone needs to be established. In this study we investigated the expression of p53 in cultured RASF by immunofluorescence, determined the expression of p53 in RA synovial tissues, and explored the in vitro induction of p53 by ionising irradiation. Furthermore, we used the SCID mouse co-implantation model of RA to analyse whether RASF which invade cartilage express p53 at sites of invasion.

\section{MATERIALS AND METHODS}

Tissue preparations

Synovial tissue specimens were obtained from RA, osteoarthritis (OA), and normal synovia from patients undergoing synovectomy, joint replacement, or trauma surgery. Samples were fixed in $4 \%$ neutral buffered formalin for 6-8 hours, dehydrated, and then embedded in paraffin using an automated tissue processor. All patients with RA fulfilled the American College of Rheumatology criteria for the diagnosis of RA. ${ }^{13}$ Ethical approval was granted by the local ethical committee and informed consent obtained from all patients.

\section{Cell culture}

Synovial fibroblasts were obtained by enzymatic digestion of synovial tissues from patients with RA, patients with OA, and normal synovial tissue as described. ${ }^{14}$ Briefly, the tissues were minced and incubated with $1.5 \%$ Dispase (Boehringer Mannheim, Rotkreuz, Switzerland) in phosphate buffered saline (PBS) for one hour at $37^{\circ} \mathrm{C}$ under continuous agitation. The cells were pelleted, resuspended, and cultured in Dulbecco's modified Eagle's medium F12 (DMEM/F12, Gibco Life Technologies, Basel, Switzerland) containing 10\% fetal calf serum, glutamine $(0.2 \mathrm{mM})$, HEPES buffer ( $10 \mathrm{mM})$, penicillin-streptomycin $(50 \mathrm{IU} / \mathrm{ml})$, and amphotericin B $(2.5 \mu \mathrm{g} / \mathrm{ml}$, all Gibco Life Technologies $)$. Isolated synovial cells were indicated with the patient number and

Abbreviations: FSFB, foreskin fibroblasts; NSF, normal synovial fibroblasts; OA, osteoarthritis; PBS, phosphate buffered saline; RASF, rheumatoid arthritis synovial fibroblasts 
Table 1 Investigation of the expression of p53 in rheumatoid arthritis synovial fibroblasts and control cells by immunofluorescence using DO7 anti-p53 antibodies

\begin{tabular}{lllll}
\hline Fibroblasts & $\begin{array}{l}\% \text { Of } \mathrm{p53} \text { positive } \\
\text { cells }\end{array}$ & Range & SD & Passages \\
\hline Rheumatoid arthritis (RA) synovial fibroblasts $(\mathrm{n}=15)$ & 3.7 & $0-7.2$ & 2.5 & $2-12$ \\
Osteoarthritis synovial fibroblasts $(n=2)$ & 0 & 0 & 0 & $4-6$ \\
Normal synovial fibroblasts $(n=1)$ & 1.6 & $0-3.2$ & 2.2 & 8,9 \\
SV40 transformed RA synovial fibroblasts & 100 & & - \\
BEAS 2B (SV40 transformed bronchial epithelial cells) & 100 & $1.4-4.4$ & 2.2 & 4,6 \\
Foreskin fibroblasts $(n=1)$ & 2.9 & & & - \\
\hline
\end{tabular}

the number of passage. Foreskin fibroblasts were received from the department of dermatology of the University Hospital in Zürich in passage three. Cells were passaged when reaching confluence and transferred to chamber slides (Lab-Tek II, Nalge Nunc Int, Napierville, IL, USA) and grown for 24-96 hours before fixation. SV40 transformed RASF, as described by Parak et al, ${ }^{15}$ and the SV40 transformed bronchial epithelial cells (BEAS 2B), obtained from G Alink from Wageningen, The Netherlands, were used as positive controls. Epithelial cells were grown in serum-free keratinocyte growth medium (SFM; Gibco Life Technologies, Basel, Switzerland).

\section{Immunohistochemistry for p53 on paraffin embedded tissues}

Tissue specimens were cut into $3 \mu \mathrm{m}$ sections, mounted on 5-aminopropyltriethoxysilane coated slides, and dried at $50^{\circ} \mathrm{C}$ for at least two hours. The sections were dewaxed in xylol and rehydrated in decreasing concentrations of ethanol, pretreated with microwave heating in citrate buffer $(0.01 \mathrm{M}$, $\mathrm{pH} 6.0$ ), and kept at $70^{\circ} \mathrm{C}$ for 30 minutes in a heat incubator for antigen retrieval.

All the following procedures were performed at room temperature. The slides were incubated with blocking solutions A and B (Vector-Laboratories, CA 94010, USA), both for 15 minutes. To decrease unspecific background reactions slides were "blocked" with $2 \%$ horse serum in $4 \%$ non-fat milk in Tris- $\mathrm{HCl}(0.1 \mathrm{M}, \mathrm{pH} 7.6)$ for 30 minutes. Primary anti-p53 antibodies (clone DO7, DAKO, Glostrup, Denmark) were diluted 1:100 (concentration $4 \mu \mathrm{g} / \mathrm{ml}$ ) and incubated for 40 minutes on the slides. DO7 anti-p53 antibodies recognise an epitope at the N-terminus of the human p53 protein (aa 19-26). Antibodies react with both wild-type and mutant p53. Mouse isotype matched IgG sera in adapted concentrations served as negative controls. As secondary antibodies, goat antimouse antibodies labelled with biotin (Jackson Immuno Research, West Grove, PA, USA, diluted $1: 200$, concentration $5 \mu \mathrm{g} / \mathrm{ml}$ ) were incubated for 30 minutes. Then, alkaline phosphatase conjugated streptavidin (DAKO, Glostrup, Denmark) was applied, also for 30 minutes, in a dilution of 1:50 (concentration $5.4 \mu \mathrm{g} / \mathrm{ml}$ ). Finally, staining was developed with the BCIP/NBT solution (Boehringer Mannheim, Rotkreuz, Switzerland) for 20-30 minutes. Between all reaction steps extensive washing was performed with Tris-HCl $(0.1 \mathrm{M}$, $\mathrm{pH}$ 7.6) and only before the application of the developing solution the slides were washed with Tris-HCl $(0.1 \mathrm{M})$ at $\mathrm{pH}$ 9.7. Tissue sections from a p53 positive neurological tumour (glioblastoma multiforme) served as a positive control.

Immunoreactivity was evaluated using a previously described method (Lee et $a l,{ }^{5}$ Sugiyama et $a l^{6}$ ). At least 10 surface areas at $\times 400$ magnification were scored, and the percentage of positive cells calculated for each patient. On average, at least 200 cells could be detected for each high power field, and thus more than 2000 cells were analysed for each specimen. For the p53 immunostaining a score of 0 to IV was assigned: $0=0 \%$ positive cells; $\mathrm{I}=<1 \%$ positive cells; $\mathrm{II}=1-5 \%$ positive cells; $\mathrm{III}=>5-20 \%$ positive cells; IV $=>20 \%$ positive cells.
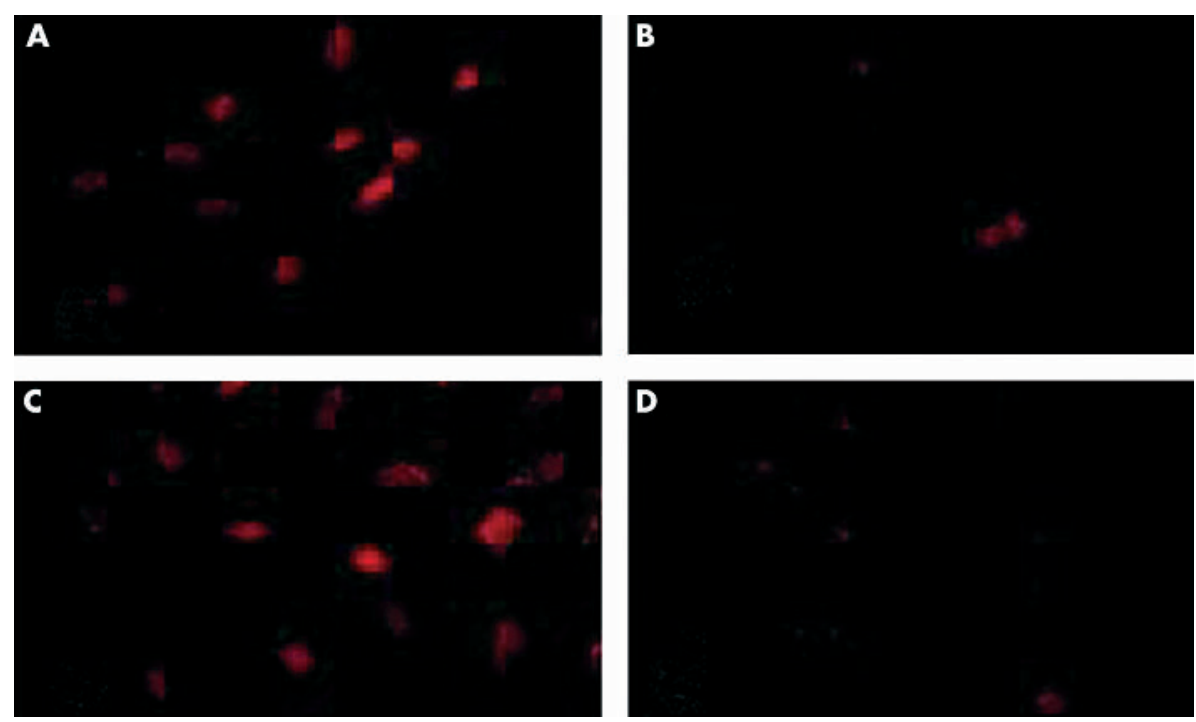

Figure 1 Immunofluorescence for p53 in irradiated and non-irradiated RASF: (A) RASF 6 in passage 3 irradiated with 10 Gy $x$ rays; (B) RASF 6 in passage 3 non-irradiated; (C) RASF 7 in passage 11 irradiated with 10 Gy $\times$ rays; (D) RASF 7 in passage 11 non-irradiated. Magnification $\times 400$. 


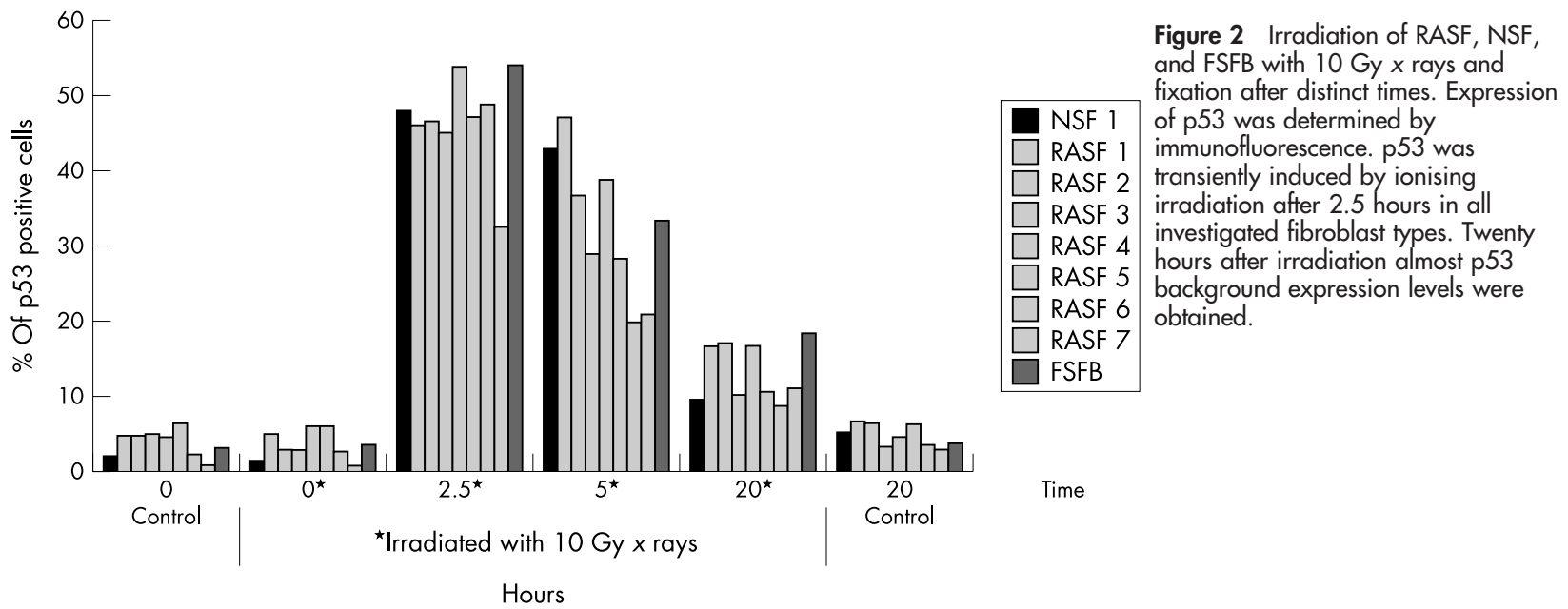

\section{Immunofluorescence of p53}

RASF in passages 2-12, OASF, and foreskin fibroblasts (FSFB) in passages $4-6$ or normal $(\mathrm{N})$ SF (passages 8 or 9) cultured on chamber slides (Labtec II, Nunc) were washed twice with PBS and then fixed with methanol/acetone (1:1) for 10 minutes at $-20^{\circ} \mathrm{C}$. Thereafter, the slides were dried at room temperature for 10 minutes and immediately processed or stored at $-20^{\circ} \mathrm{C}$. Rehydrated in Tris- $\mathrm{HCl}(0.1 \mathrm{M}, \mathrm{pH} 7.6)$, the slides were blocked with $2 \%$ horse serum and $4 \%$ non-fat milk in Tris- $\mathrm{HCl}$ for 30 minutes. After washing with PBSTween $(0.05 \%)$, the slides were incubated with primary antip53 antibodies in a dilution of 1:1000 in PBS-Tween (DO7, concentration $0.4 \mu \mathrm{g} / \mathrm{ml}$ ) for 30 minutes at room temperature. As negative controls mouse isotype matched IgGs were used. After several washing steps Cy3 conjugated sheep antimouse sera (DIANOVA, distributed by Milan Analytica Ag, La Roche, Switzerland) diluted 1:1000 (concentration $0.14 \mu \mathrm{g} / \mathrm{ml}$ ) in PBS-Tween were applied as secondary antibodies for 30 minutes at room temperature. Rinsed in PBS, the slides were finally mounted in fluorescent mounting
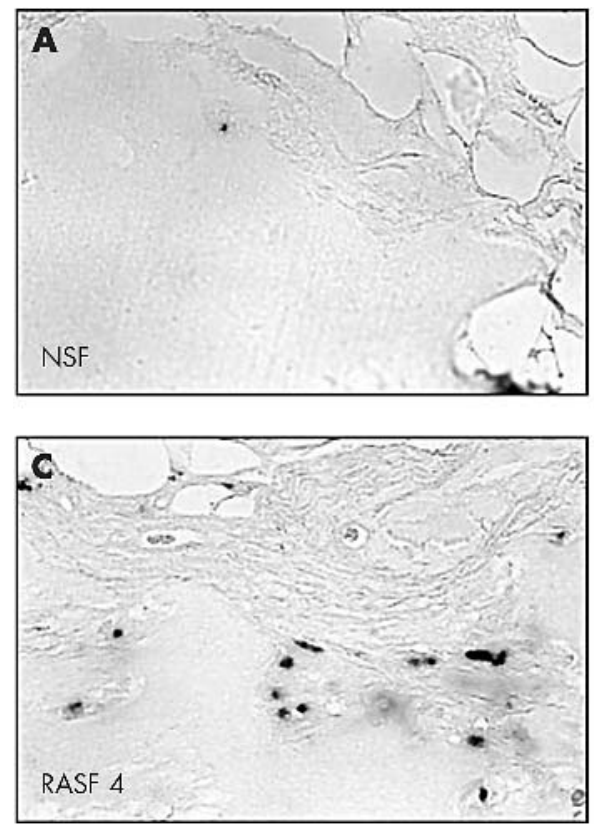

medium (DAKO) and analysed with a Zeiss immunofluorescence microscope at a wavelength of 515-545 nm. The immunostaining was evaluated by counting. At least 10 high power fields at $\times 400$ magnification with a total number of 90-200 evaluated cells were scored.

\section{Irradiation of cultured fibroblasts with $\mathrm{x}$ rays}

RASF in passages 3 to 11, FSFB in passage 5 , and NSF in passage 9 were grown on chamber slides, and irradiation ( $10 \mathrm{~Gy}$ ) was carried out at room temperature with a Pantak Therapax $300 \mathrm{kV} x$ ray unit at $0.7 \mathrm{~Gy} / \mathrm{min}$. After $0,2.5$, 5, or 20 hours cells were fixed as described above. Appropriate non-irradiated controls were used at 0 and 20 hours. Expression of p53 was determined by immunofluorescence, and the percentage of positive cells was evaluated by counting.

\section{SCID mouse experiments}

SCID mice $(\mathrm{n}=28$ ) were obtained from Charles Rivers $\mathrm{GmbH}$ (Sulzfeld, Germany) and kept permanently under sterile
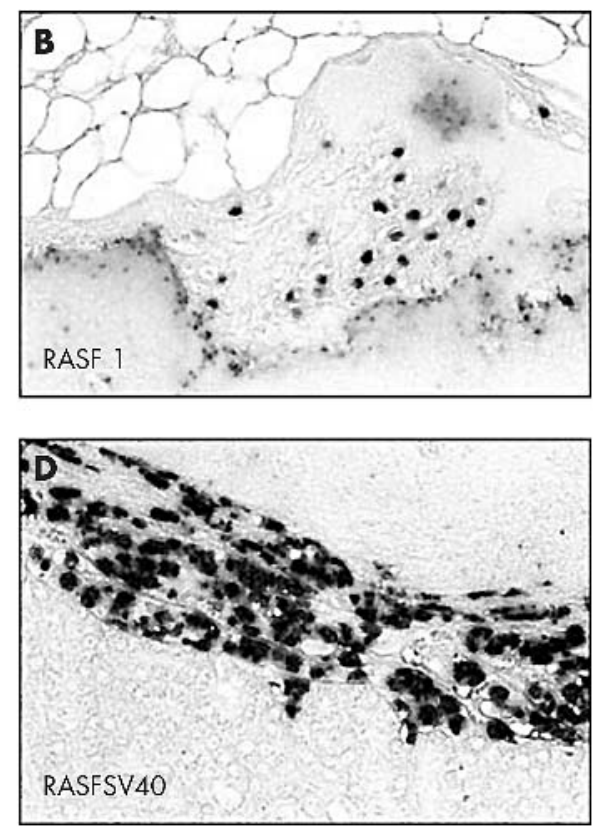

Figure 3 Immunohistochemistry of p53 using DO7 antibodies in SCID mice sections of NSF, RASF, and SV40 transformed cells. In NSF, only limited invasion, but hardly any p53 signal was detectable. In RASF, expression of p53 was found in some cartilage invading cells. Strong p53 expression occurred in SV40 transformed RASF (positive control). Magnification $\times 400$. 


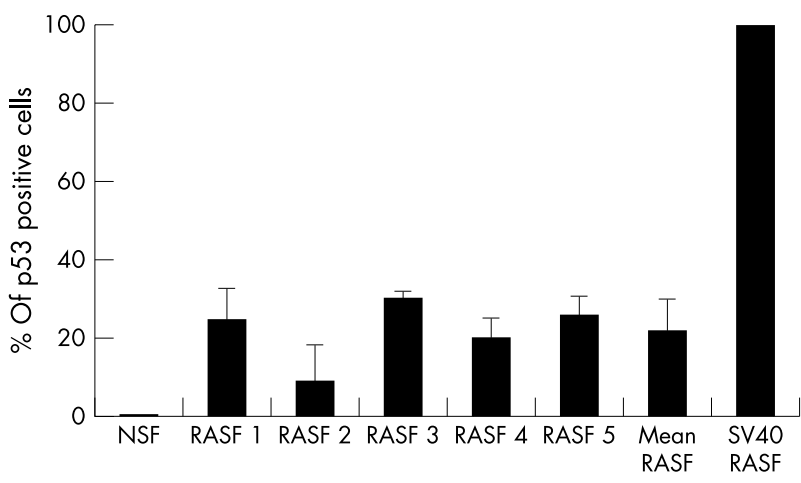

Figure 4 Quantification of $\mathrm{p} 53$ positive cells at sites of invasion in the SCID mouse co-implantation model of RA. Data are expressed as means (SD). On average, p53 was expressed during the invasive process in $20 \%$ of cartilage invading RASF. In vitro, the same RASF were largely p53 negative $(<5 \%)$.

conditions. Implantation of RASF and NSF together with normal human cartilage was performed as described. ${ }^{14}$ Additionally in one SCID mouse SV40 transformed synoviocytes were engrafted to serve as positive control. Cells were trypsinised and dissolved in an inert collagen sponge (Gelfoam; Pharmacia, Upjohn, Dübendorf, Switzerland). Sponges were co-implanted with pieces of human articular cartilage of $1 \mathrm{~mm}^{3}$ size under the renal capsule of SCID mice. Mice were anaesthetised by intraperitoneal injection of Xylocain (lidocain hydrochloride, $0.014 \mathrm{mg} / \mathrm{g}$ of body weight; Astra Pharmaceutica, Dietikon, Switzerland) and Ketalar (ketamine hydrochloride, $0.09 \mathrm{mg} / \mathrm{g}$ of body weight; ParkeDavis, Baar, Switzerland) in an isotonic solution. An incision was made on the left flank and the left kidney was carefully exteriorised. A small incision of the renal capsule was performed with a forceps and sponge and cartilage were coengrafted adjacent to the kidney. Peritoneum and skin were closed using 5-0 Prolene suture material. After 60 days, mice were killed, and the implants were fixed in $4 \%$ buffered formalin and embedded in paraffin according to standard procedures. Paraffin embedded sections were stained with haematoxylin and eosin, or analysed for the expression of p53 with anti-p53 antibodies as described above. The immunohistochemistry of the SCID mice sections was repeated twice. Invasion into the cartilage was quantified according to a semiquantitative score ranging from 0 to IV referring to the number of invading cells and the number of affected cartilage sites (0, no invasion; 0.5 , invasion of $1-2$ cell layers; I, invasion of 3-5 cell layers; I.5, invasion of 3-5 cell layers at three independent sites of the cartilage; II, invasion of 6-10 cell layers; II.5, invasion of 6-10 cell layers at three independent sites; III, invasion of $>10$ cell layers; III.5, invasion of $>10$ cell layers at two independent sites; IV, invasion of $>10$ cell layer at three or more sites of the cartilage). Expression of p53 was determined by counting the number of p53 positive invading cells in comparison with all invading cells.

\section{Statistical analysis}

For statistical analysis, the Mann-Whitney U test was used. Values of $\mathrm{p}<0.05$ were considered to be significant. Data were expressed as the mean (SD).

\section{RESULTS}

Expression of p53 in untreated or irradiated RASF

The in vitro expression of p53 in untreated RASF was low in comparison with the SV40 transformed cells. In average, $3.7 \%$ of RASF expressed p53 (table 1) and this was slightly higher than in OASF, FSFB, and NSF, but did not reach statistical significance, even when the data of the control fibroblasts were pooled $(\mathrm{p}>0.05)$. p53 was transiently inducible by ionising irradiation. Immediately after irradiation, the expression of p53 in all cells was about $4 \%$ and this did not differ from non-irradiated controls fixed at 0 or 20 hours. Two and a half hours after irradiation the percentage of p53 expressing cells increased remarkably about 10-15 times, reaching a maximum of 33-54\% (figs 1 and 2). After 20 hours, only $10-20 \%$ of the cells still expressed p53 in the nucleus. In the dose response and in the time course of the p53 induction after irradiation no major differences were detected between RASF, NSF, and FSFB cell cultures. Non-irradiated, SV40 transformed RASF and BEAS 2B cells, with a strong nuclear staining for p53, served as positive controls. Appropriate IgG controls were negative (not shown).

\section{SCID mice experiments}

In agreement with previous investigations, ${ }^{3}$ RASF from five different patients invaded the co-engrafted cartilage significantly stronger $(\mathrm{p}<0.01)$ than normal synovial fibroblasts (invasion scores $2.7-3.5 \vee 1.1-1.5$, respectively). SCID mice sections from these experiments were stained with DO7 antip53 antibodies. NSF showed very limited invasion and negligible staining for $\mathrm{p} 53$. On the other hand, RASF showed a strong cartilage invasion and $20 \%$ of the cells invading the cartilage were found to express p53 in the nucleus (figs 3 and 4 ). Of note, the cells not invading the articular cartilage and located outside the invasive zones were completely negative for $\mathrm{p} 53$.

\section{Immunohistochemistry of p53 in synovial tissues}

The expression of p53 in synovial tissues from RA, OA, and normal synovia was low in comparison with the neurological tumour (glioblastoma multiforme) as determined by immunohistochemistry using DO7 anti-p53 antibodies. In RA tissues $0-7 \%$ of the cells stained positive for p53 with a mean of $1.9 \%$ (table 2, fig 5). 13/14 RA samples showed an expression of $\mathrm{p} 53$ in $<5 \%$ of the cells. Positive signals were mainly located in the sublining. The expression of p53 in OA synovial tissues was not significantly different from that in RA synovial tissues. None of the normal synovia

Table 2 Quantification of the expression of p53 in rheumatoid arthritis and control tissues by immunohistochemistry using a scoring system from 0 to $\mathrm{IV}^{*}$

\begin{tabular}{lllllllll}
\hline & 0 & I & II & III & IV & Mean (\%) & Range & SD \\
\hline Rheumatoid arthritis $(n=14)$ & $3 / 14$ & $3 / 14$ & $7 / 14$ & $1 / 14$ & & 1.9 & $0-7.2$ & 2.1 \\
Osteoarthritis $(n=3)$ & & $2 / 3$ & $1 / 3$ & & & 1.5 & $0.7-3.1$ & 1.4 \\
Normal synovia $(n=3)$ & $3 / 3$ & & & & $3 / 3$ & $>50$ & & \\
Neurol. tumour (positive control) & & & & & $3 / 3$
\end{tabular}

*Percentage of p53 positive cells: $0=0 \% ; I=<1 \% ; \|=1-5 \%$; III = $>5-20 \%$; IV = $>20 \%$. 

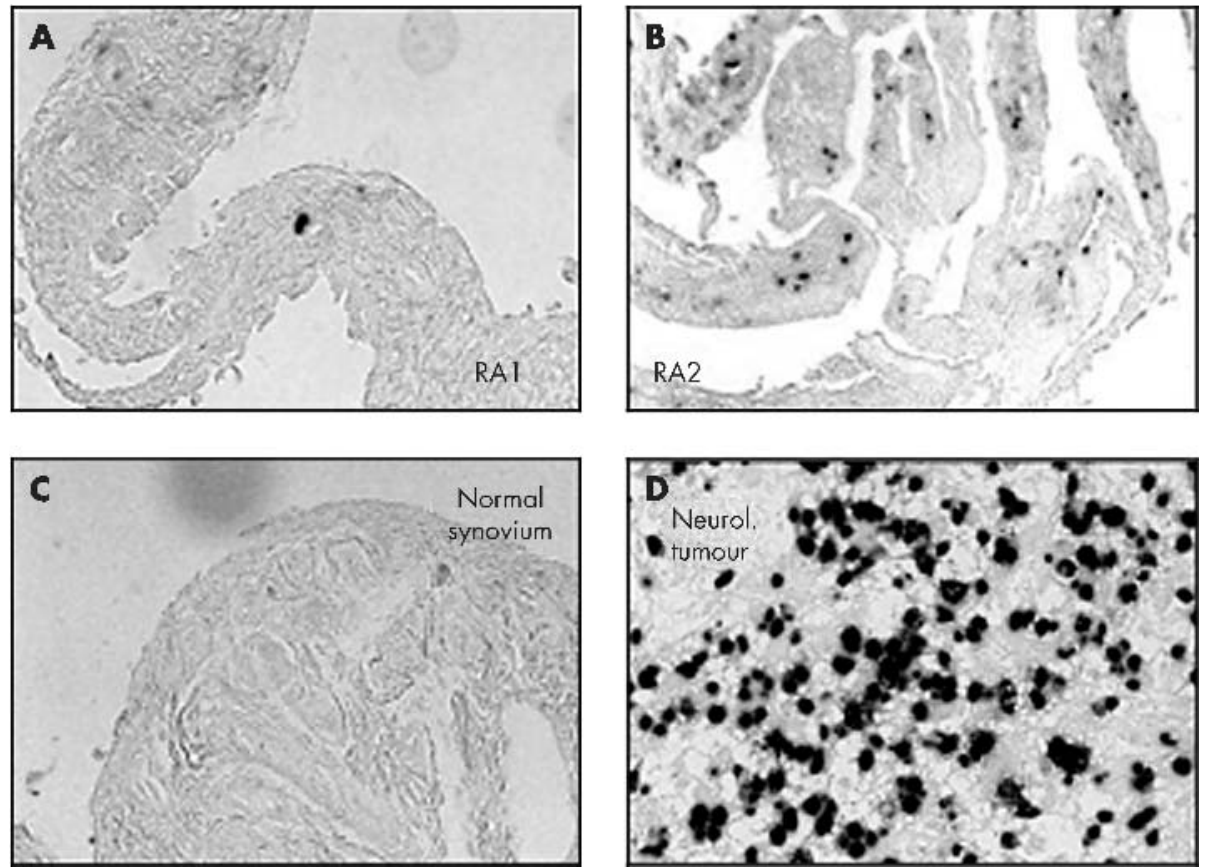

Figure 5 Immunohistochemistry of p53 with DO7 antibodies of RA tissue specimens and controls. Limited expression of p53 was detected in RA synovium, but no expression in normal synovium. Strong nuclear p53 expression was found in a neurological tumour (positive control). Magnification RA2 $\times 200$, all others $\times 400$.

demonstrated any signal for p53, and this difference was significant for the expression of p53 in RA tissues $(\mathrm{p}=0.032)$. Sections incubated with mouse control serum were negative.

\section{DISCUSSION}

This study was designed to determine whether expression of p53 in RASF could be associated with the invasive behaviour. Therefore, we investigated the functional p53 response in RASF grown in vitro and the induction of p53 in RASF engrafted into the SCID mouse co-implantation model of RA.

In vitro, the expression of $\mathrm{p} 53$ as determined by immunofluorescence in untreated RASF was $<5 \%$. This is in line with previous results ${ }^{4}$ reporting p53 staining in $10 \%$ for unstimulated fibroblast-like synoviocytes, while dermal fibroblasts showed a p53 expression in about $5 \%$ of the cells. As shown in figs $\mathrm{l}$ and 2, p53 was transiently inducible in RASF, NSF, and FSFB by $x$ ray irradiation, which did not differ between all the types of fibroblasts examined. The transient induction suggests the presence of wild-type p53 in the majority of synovial fibroblasts. This is in line with studies showing either no p53 mutations or only in a small cell population of RASF. ${ }^{9-11}$ In this context, it is interesting that Migita et al ${ }^{16}$ have demonstrated a functional p53 response in RASF by treatment with the proteasome inhibitor MG-132. This resulted in both an accumulation of p53 and a p 21 mediated Gl arrest of the cell cycle.

Most interestingly, our study shows that in in vivo experiments using SCID mice p53 was induced in RASF at sites of cartilage invasion, although the vast majority of RASF were, in vitro, p53 negative. The number of p53 positive cells was $20 \%$, but not all cells at sites of invasion stained positively for p53. Moreover, RASF located outside the invasive zones were p53 negative. An alternative explanation to the induction of p53 might be that cells expressing p53 have a selective advantage when invading the cartilage explant. In that case, cells expressing mutant p53 would potentially be more invasive. However, this appears not to be likely because the cells were grown in vitro over several passages and cells carrying functional relevant p53 mutations should become the predominant cell population, which was clearly not the case.

Our results are consistent with investigations in rat adjuvant arthritis ${ }^{17}$ as well as collagen induced arthritis. ${ }^{18}$ In these models the expression of p53 occurs in established arthritis, suggesting also that the expression of p53 is a consequence and not the cause of the inflammatory process. These results suggest that p53 induction is a normal consequence of inflammation. In addition, the present study indicates that $\mathrm{p} 53$ can be induced during the invasive process in RASF even in the absence of inflammation.

The finding that expression of p53 is a consequence or "adaptive" response to certain stimuli is consistent with the finding of wild-type p53 expression in various inflammatory diseases such as OA, reactive arthritis, inflammatory bowel disease, psoriasis, Helicobacter pylori infection, and many others. ${ }^{19}$ Just recently, Yamanishi and coworkers presented evidence for a functional suppressive role of p53 in collagen induced arthritis, because p53 - / - mice showed a more pronounced inflammation. ${ }^{18}$ The authors concluded that $\mathrm{p} 53$ is induced in the rheumatoid joint with protective functions such as cell cycle arrest, apoptosis, or suppression of matrix metalloproteinases. Similarly, we suggest that an adaptive p53 response occurs also in the non-inflammatory SCID mouse co-implantation model of RA.

In summary, we presented in vitro and in vivo evidence for a functional p53 response in RASF. These data suggest that p53 at sites of cartilage invasion could be induced during the destructive process driven by activated RASF.

\section{ACKNOWLEDGEMENTS}

We thank Maria Comazzi and Ferenc Pataky for their excellent technical assistance.

Christian A Seemayer was supported by the Swiss National Science Foundation (grant 32-64142.00 to Steffen Gay), Christian A Seemayer, Stefan Kuchen, and Veronika Řihošková were supported by the EMDO foundation. 


\section{Authors' affiliations}

S Kuchen, M Neidhart, P Kuenzler, V Řihošková, R E Gay, B A Michel,

S Gay, Centre of Experimental Rheumatology and WHO Collaborating Centre for Molecular Biology and Novel Therapeutic Strategies for Rheumatic Diseases, Department of Rheumatology, University Hospital Zürich, Switzerland

C A Seemayer, Institute of Pathology, University Hospital, Basel, Switzerland and Centre of Experimental Rheumatology and WHO Collaborating Centre for Molecular Biology and Novel Therapeutic Strategies for Rheumatic Diseases, Department of Rheumatology, University Hospital Zürich, Switzerland

E Neumann, U Müller-Ladner, Department of Internal Medicine I, University of Regensburg, D-93042 Regensburg, Germany

M Pruschy, Radiooncology, Department of Oncology, University Hospital Zürich, $\mathrm{CH}-8091$ Zürich, Switzerland

W K Aicher, Clinical Research Unit for Rheumatology, Tübingen, Germany

G S Firestein, Division of Rheumatology, Allergy and Immunology,

UCSD School of Medicine, La Jolla, CA 92093, USA

\section{REFERENCES}

1 Gay S, Gay RE, Koopman WJ. Molecular and cellular mechanisms of joint destruction in rheumatoid arthritis: two cellular mechanisms explain joint destruction? Ann Rheum Dis 1993;52(suppl I):S39-47.

2 Muller-Ladner U, Gay RE, Gay S. Activation of synoviocytes. Curr Opin Rheumatol 2000;12:186-94.

3 Muller-Ladner U, Kriegsmann J, Franklin BN, Matsumoto S, Geiler T, Gay RE, et al. Synovial fibroblasts of patients with rheumatoid arthritis attach to and invade normal human cartilage when engrafted into SCID mice. Am J Pathol 1996; 149:1607-15.

4 Firestein GS, Nguyen K, Aupperle KR, Yeo M, Boyle DL, Zvaifler NJ. Apoptosis in rheumatoid arthritis: p53 overexpression in rheumatoid arthritis synovium. Am J Pathol 1996;149:2143-51.

5 Lee CS, Portek I, Edmonds J, Kirkham B. Synovial membrane p53 protein immunoreactivity in rheumatoid arthritis patients. Ann Rheum Dis 2000;59:143-5.

6 Sugiyama M, Tsukazaki T, Yonekura A, Matsuzaki S, Yamashita S, Iwasaki K. Localisation of apoptosis and expression of apoptosis related proteins in the synovium of patients with rheumatoid arthritis. Ann Rheum Dis 1996;55:442-9.

7 Tak PP, Smeets TJ, Boyle DL, Kraan MC, Shi Y, Zhuang S, et al. p53 overexpression in synovial tissue from patients with early and longstanding rheumatoid arthritis compared with patients with reactive arthritis and osteoarthritis. Arthritis Rheum 1999;42:948-53.

8 Firestein GS, Echeverri F, Yeo M, Zvaifler NJ, Green DR. Somatic mutations in the p53 tumor suppressor gene in rheumatoid arthritis synovium. Proc Natl Acad Sci USA 1997;94:10895-900.

9 Reme T, Travaglio A, Gueydon E, Adla L, Jorgensen C, Sany J. Mutations of the p53 tumour suppressor gene in erosive rheumatoid synovial tissue. Clin Exp Immunol 1998;111:353-8.

10 Inazuka M, Tahira T, Horiuchi T, Harashima S, Sawabe T, Kondo M, et al. Analysis of $\mathrm{p} 53$ tumour suppressor gene somatic mutations in rheumatoid arthritis synovium. Rheumatology (Oxford) 2000;39:262-6.

11 Kullmann F, Judex M, Neudecker I, Lechner S, Justen HP, Green DR, et al. Analysis of the p53 tumor suppressor gene in rheumatoid arthritis synovial fibroblasts. Arthritis Rheum 1999;42:1594-600.

12 Pap T, Aupperle KR, Gay S, Firestein GS, Gay RE. Invasiveness of synovial fibroblasts is regulated by p53 in the SCID mouse in vivo model of cartilage invasion. Arthritis Rheum 2001;44:676-81.

13 Arnett FC, Edworthy SM, Bloch DA, McShane DJ, Fries JF, Cooper NS, et al. The American Rheumatism Association 1987 revised criteria for the classification of rheumatoid arthritis. Arthritis Rheum 1988;31:315-24.

14 Pap T, van der Laan WH, Aupperle KR, Gay RE, Verheijen JH, Firestein GS, et al. Modulation of fibroblast-mediated cartilage degradation by articular chondrocytes in rheumatoid arthritis. Arthritis Rheum 2000;43:2531-6.

15 Parak WJ, Dannohl S, George M, Schuler MK, Schaumburger J, Gaub HE, et al. Metabolic activation stimulates acid production in synovial fibroblasts. J Rheumatol 2000;27:2312-22.

16 Migita K, Tanaka F, Yamasaki S, Shibatomi K, Ida H, Kawakami A, et al. Regulation of rheumatoid synoviocyte proliferation by endogenous p53 induction. Clin Exp Immunol 2001;126:334-8.

17 Tak PP, Klapwijk MS, Broersen SF, van de Geest DA, Overbeek M, Firestein GS. Apoptosis and p53 expression in rat adjuvant arthritis. Arthritis Res 2000;2:229-35.

18 Yamanishi Y, Boyle DL, Pinkoski MJ, Mahboubi A, Lin T, Han Z, et al. Regulation of joint destruction and inflammation by $\mathrm{p} 53$ in collagen-induced arthritis. Am J Pathol 2002;160:123-30.

19 Tak PP, Zvaifler NJ, Green DR, Firestein GS. Rheumatoid arthritis and p53. how oxidative stress might alter the course of inflammatory diseases. Immunol Today 2000;21:78-82. 